\title{
THE ROLE OF FAMILY IN DEAF CHILDREN'S THEORY OF MIND DEVELOPMENT
}

\author{
Joanna Kossewska
}

\begin{abstract}
The present review aims to provide a comprehensive discussion of the relationship between family and Deaf children's theory of mind (ToM) development. The discussion will present the differences between the Deaf and hearing family communication contexts. The paper will also point out the role of maternal sign language ability specifically in Deaf children of hearing parents and the training perspective.
\end{abstract}

\section{Key words}

Family, Deaf child, theory of mind, communication contexts, maternal sign language ability, training, perspective, communication competence, interactions, cognitive perspectives.

\section{The Deaf children family relationship in the context of rehabilitation}

The modern approach to the rehabilitation of disabled children has changed with regard to the role of family in the rehabilitation process. (Dykcik, 2001). The change particularly concerns the first years of life and means that when receiving the diagnosis parents become active participants of all interventions and activities supporting their child's development. Family is therefore the most appropriate environment both for the natural development of a child and for the rehabilitation process, especially for the early intervention aimed at preparing the child for participation in later activities conducted by various educational and rehabilitative institutions. (Twardowski, 2003). An important factor influencing the effectiveness of family involvement in the rehabilitation process is family resources, i. e. structural and dynamic properties of the family system, which limit the family's susceptibility to hurt and support its mechanisms of handling stressful situations. Family resources may have a very concrete, material form, or an ethical/ spiritual form; they may also be psychological properties of particular family members or of the whole family system (Plopa, 2004). 
Assuming that family is the most appropriate environment for the development and rehabilitation of children with impaired hearing, especially in early childhood, it seems essential to consider its influence on the development of children's theory of mind. A particularly important question is the influence of family resources, or psychological properties of individual family members, on the process of theory of mind development.

Communication skills that enable family members to communicate with a Deaf child can be considered such an essential family resource. Is the process dependent on the means of communication within the family, or on the significant others'/the child's communication competence? Finding the answers to the above questions may help improve the process of supporting the theory of mind development in Deaf children.

\section{Theory of mind - its role and development}

Theory of mind is the competence beneath the basis of the ability to predict and explain the behavior of other people; both significant others as well as strangers. It is deep-seated mental competence which helps the process of explanation of other people's behavior and is based on understanding mental states, such as beliefs, desires and intentions of those people. Individuals understand the behavior of others in terms of their beliefs about the world. The term "Theory of Mind" was coined by David Premack and Guy Woodruff (1978) who tested a chimpanzee's ability to predict a person's behavior by means of mental state attribution.

A theory of mind is defined as the ability to infer other people's mental states (thoughts, beliefs, desires, intentions, etc) and the ability to use this information to interpret the meaning of their communication, make sense of their behavior and predict what they will do next. Theory of mind development begins almost at birth because a human newborn is is sensitive to social stimuli. Theory of mind seems to develop in complexity through the early childhood years.

Baron-Cohen (1995) suggests that most children begin to develop a theory of mind when they can recognize primitive mental states like "desire". This ability emerges around nine months of age and manifests in skills like joint attention (Baron-Cohen, 1995; Tomasello, Knuger, \& Rather, 1993). Children of approximately eighteen months of age learn to follow another's gaze in order to see what they are looking at, as well as to comment on what they see 
in the environment. By the time when toddlers starts to talk they talk about the actions in the terms of mental states. At the age of 18-30 months children refer to a range of mental states such as emotions, desires, beliefs, thoughts, dreams, pretence (Bretherton, Beeghly, 1982). By two years of age, children begin to understand a full range of mental state words, such as, think, know, want, desire, believe, remember, forget, pretend, etc. By age four, children are aware that others hold views that differ from their own, at which point they are considered to have a full-blown theory of mind (Baron-Cohen, 1995).

Results from a study by Wellman and Estes (1986) indicate that by age three children have the capacity to deal with the nature and function of the mind. Overall, most of recent studies have suggested that children as young as 3 to 4 years of age, and certainly by 5 to 6 years of age, have capacities to conceptualize themselves and others as entities that think, believe, doubt, wonder, and pretend.

By the age of 4 years the child's theory of mind is well developed and they are able to pass false belief task (Wimmer, Perner, 1983). First-order false belief tasks (e.g., "Sally thinks it's x, when really it's y") or second-order false belief tests (e.g., "Sally thinks Mary thinks x, but both Sally and Mary are wrong") are the main ways in which researchers assess a person's theory of mind. The main findings are that 4-year-olds pass first order false belief task, whilst 6year-olds pass second order false belief tasks (Perner \& Wimmer, 1985; Sullivan, Zaitchik \& Tager-Flusberg, 1994; Wimmer \& Perner, 1983). Passing these tests should really be considered as relatively early points in the acquisition of a theory of mind, and there is a lot of development of "mindreading" beyond 4-6 years old.

The next step of theory of mind development could be tested by three more "advanced" tests (Baron-Cohen, Jolliffe, Mortimore \& Robertson, 1997; Baron-Cohen, Wheelwright \& Jolliffe, 1997; Happe, 1994). Happe's task, for example, involves the detection of sarcasm, bluff, irony, and double-bluff. These are not well understood until 8 years old. At the 9-11 year old level socially normal individuals have the ability to recognize when someone has committed a faux pas. A faux pas is defined as an action when a speaker says something without considering if it is something that the listener might not want to hear or know, and which typically has negative consequences that the speaker never intended. (Baron-Cohen et al, 1999). 


\section{Family background and theory of mind development}

The theory of mind development is influenced by exposure to conversation about mental states (Jenkins \&Astington, 1996; Perner, Ruffman, \& Leekman, 1994). Candida Peterson and Michael Siegal (1997) believe that essential factors are: the amount of conversational situations in which a child can participate with a fluent communicator, as well as the child's language development. Some research showed that there is a relationship between verbal ability and ToM in normally developing children (Jenkins \& Astington, 1996, Białecka-Pikul, 2002). However, communication difficulties may prevent some children from being able to successfully converse with others. DeVilliers and deVilliers (2000) have emphasized that performance on false belief tasks depends on understanding complex language and that individual differences may reflect differences in language ability. Several studies have found that children with better language skills perform better on false belief tasks (Astington, Jenkins, 1999). The idea that the accurate use of linguistic terms describing mental states, such as "think", "know" and "remember" requires them to be understood. If a child does not understand what these words mean, then they are likely to fail false belief tasks.

It is known that families differ from one another in the extent to which parents are "mind-minded" (Meins \& Fernyhough, 1999). Perhaps highly mind-minded parents, who ascribe beliefs and other cognitive states to their offspring from an early age, may interact with their children in ways that foster rapid ToM growth. At the same time, mind-minded parents might also plan large, closely spaced families so as to give each of their offspring the benefit of social interaction with like-minded siblings.

More knowledgeable conversational partners consciously or unconsciously control children's exposure to mental state language. Particular kinds of mother talk assume more importance at different points in time. The most significant other is the mother who usually takes care of the child as well as talks to him/her using mental terms describing stories, poetry and reality.

Maternal talk about others' thoughts and knowledge becomes very important and starts quite early. It was found that the language used to talk about children's desires with 15-month-olds was related to their later understanding of mental states (Taumoepeau, Ruffman; 2006). Recent research by Taumoepeau, Ruffman (2008) shown the maternal talk about mental states has specific patterns and that the incremental exposure to mental 
state talk may help children's later mental state understanding. Mother talk about others' thoughts and knowledge becomes increasingly important later in the same children's development. Mothers' structuring of input reduces the burden of learning for children in that the input they receive is tailored to their current level of understanding. Mothers begin with desires that have a salient manifestation in emotional expression and actions and have great relevance for the child. Mothers usually focus on the child first and describe their desires, which will help children connect their own, very relevant, internal experiences to mental states. Then they focus on more abstract mental concepts-thoughts and knowledge-as they relate to other people.

Early theory of mind development increases within the accepting contact with a significant other. Attachment is an emotional bond to another person. According to Bowlby's theory, the earliest bonds formed by children with their caregivers have a tremendous impact that continues throughout life. These bonds were described as attachment understood as a lasting psychological connectedness between human beings (Bowlby, 1969). Attachment also serves to keep the infant close to the mother, thus improving the child's chances of survival. The best outcome of early social development is secure attachment which means that children exhibit distress when separated from caregivers and are happy when their caregiver returns. But they feel secure and able to depend on their adult caregivers. When the adult leaves, the child may be upset but he or she feels assured that the parent or caregiver will return. Such adaptive capacities are the outcome of a secure attachment. Mental state understanding is therefore related to attachment security (Fonagy et al., 1997).

Language ability and emotional understanding within family might be also influenced with parental occupational class and the level of mother's education and those factors may also be good predictors of theory of mind development (Cutting and Dunn, 1999).

Some researchers have pointed out that family background may also account for some differences. Several studies have shown that children who are exposed to high levels of social interaction with siblings and caregivers perform better on false belief tasks than do children who are not exposed to such social interactions (Dunn, 1991; Perner, Ruffman, \& Leekam, 1994). It was found that children with older brothers or sisters succeed in theory of mind tasks earlier than only children or those with a younger sibling (Ruff- 
man et al., 1998). Older siblings provide opportunities through play and discussion for younger children to learn about the mental states of others. The evidence from studies in both the United States and Britain show that young children in these countries grow up in a world in which there is much conversation within families about the feelings and behavior of others and about their motives, intentions, and the permissibility of their actions (Dunn, 1991). Similarly, other research findings suggest that a home environment with more interactions may provide more opportunities for learning about thought-behavior relations (Perner, Ruffman, \& Leekam, 1994). In the experimental study done in Australia examining the development of a theory of mind in children aged 3 to 5 years it was found that children who had a sibling outperformed only-children. However, the presence of a very young infant, or of siblings who were teenagers or young adults, exerted no benefit. However, younger child siblings and twins were just as helpful as older child siblings. In numerous families there are many social influences in which the opportunity to play, converse, and disagree in distinctively childish ways with brothers and sisters provides unique insights into the workings of the human mind as well as to communicate about mental states (Peterson, 2000). The longitudinal study where a package of standard ToM tasks was designed twice at time 1 and at time 2 to children who were an average of 14 months older. It found significant associations between children's advanced performance on standard ToM tests and their access at home to larger numbers of childaged siblings with whom to play and converse. The access to interaction with child-aged siblings at home does have special value for advancing the understanding of false belief (McAlister, Peterson, 2007).

\section{Theory of mind in Deaf}

The first study in the field of theory of mind in the Deaf by Peterson and Siegal (1995) revealed that $65 \%$ of profoundly Deaf Australian children aged 8-13 using Auslan (Australian sign language) to communicate failed the false belief test. They reported that only $35 \%$ of them passed a version of the classic "Sally-Anne" task. Peterson and Siegal (1995) found that the majority of a group of Deaf children aged 8 to 13 years with hearing parents did not pass a false-belief test that most hearing children passed around 4 or 5 years of age. The level of performance shown by Deaf children did not differ significantly from that reported for autistic children of a comparable 
(nonverbal) mental age. These results were replicated in a later comparison of Deaf and autistic children across a wider age range using a wider range of tests (Peterson \& Siegal, 1997, 1999, 2000).

More recent research indicates that Deaf children are not impaired in theory of mind development but just delayed in this process. It is not a developmental impairment as in autism (Peterson \& Siegal, 1999). However, that delay is quite serious compared to hearing children - in some cases Deaf children do not reliably understand false belief until early adolescence. Deaf children of hearings parents have been consistently found to do poorly on false-belief tasks, when compared to Deaf children of Deaf parents (Courtin \& Melot, 1998; Peterson \& Siegal, 1995; de Villiers \& de Villers, 2000; Schick, de Villiers, de Villiers, \& Hoffmeister, 2007). Deaf children aged 5-12 years solve tests focused on theories of mind better than 3-year-olds but not as well as 4-year-olds. This delay is quite serious because the research did not find Deaf children of hearing parents to consistently display accurate understanding of false belief until after the age of 15 years (Russell et al., 1998), although the background mechanism itself is not damaged and the problem is not related to hearing impairment per se but rather to some aspects of the language context.

The role of language has often been perceived as fundamental to theory of mind development in hearing children, which was described previously (Astington \& Jenkins, 1999; de Villiers, 2000; de Villiers \& de Villiers, Biłecka-Pikul, 2002), thus it should also be important to the Deaf.

It is obvious that the Deaf children group is not homogeneous because more than $90 \%$ of Deaf children have hearing parents, while less than $10 \%$ of hearing parents with Deaf children are fluent signers. Many hearing parents with Deaf children cannot converse easily with their Deaf child about a variety of topics (Marschark, 1993).

One area where communication is difficult includes conversations about mental states. For many hearing parents, they are working on their own signing abilities while learning to converse with their Deaf child. As a result of limited exposure to language, Deaf children will be delayed in gaining conversational access to information about the thoughts and feelings of others, which may interrupt or delay ToM development (Moeller \& Schick, 2006). It seems that many Deaf children will be delayed in gaining conversational access to information about the intangible thoughts and feelings of others. According to Peterson and Siegal $(1995,2000)$, the primary cause of a delayed 
development of ToM is the lack of access to conversations. Strong evidence for such a general conclusion was found in research comparing false beliefs in Deaf children who are native signers of a sign language (usually the second generation of Deaf children who have been raised by signing Deaf parents) and late signers - Deaf children of hearing parents (often learning sign language only once at school).

Studies composed of different tasks show interesting, however differential results due to the fact that in many studies late signers are older than the compared hearing children, when they typically pass false belief tasks. So it is difficult to determine how native signers compare with hearing peers in terms of development of false belief understanding if different age groups are taken into account. Peterson and Siegal (2000) summarised the results of 11 separate investigations from different cultures and educational systems involving profoundly Deaf children and false belief tests and found consistent support for the finding that late signers are seriously delayed in acquiring theory of mind, whereas the delay amongst native signers was not so marked. The value of the child's social and emotional development depends on visual and tactile communication techniques of interacting developing naturally between a Deaf child and a Deaf parent.

Peterson and Siegal's (1995) findings are consistent with the proposition that ToM development is dependent upon appropriate social experience; this is called the "early conversational hypothesis". Most of the children in their study were raised in homes with no proficient signing family members. Therefore, research suggests that the children's opportunities for learning about mental states through conversation and other types of interaction were limited. Another line of research has found that Deaf children from Deaf households develop false-belief concepts at the same age as children of normal hearing (Peterson \& Siegal, 2000; Schick et al., 2007). In fact, Deaf native signers have been found to converse as frequently about mental states and past and future occurrences with their Deaf children as hearing parents do with their hearing children (Meadow, Greenberg, Erting, \& Carmichael, 1981). Furthermore, hearing children who are consistently exposed to sophisticated talk with adults and older children, both at home and in the extended community, demonstrate more advanced false-belief understanding (Lewis, Freeman, Kyriakidou, Maridaki-Kassotaki, \& Berridge, 1996). As more research has connected ToM development and the "early language hypothesis", there has been recognition and utilization of verbal ability measures in studies 
of ToM development in hearing children. Research has progressed to include administering verbal ability measures in studies of Deaf children's ToM development. A growing recognition of the relationship between children's ToM and social dialogue has also produced research directly examining hearing mothers' mental state talk with their hearing children. This is often gauged by talking about the past or sharing in a task (Welch-Ross, 1997; Ruffman, Slade, \& Crowe, 2002).

Peterson et al. (2005) have shown that only a third of the late-signers aged 5.5-13.2 years could pass a false belief task, whereas $60 \%$ of Deaf adolescents from hearing families could not understand another person's false beliefs. It ought to be emphasized, however, that the findings of different scientists from the studies comparing different age groups are divergent, depending on age, and depict smaller developmental delays in ToM development. According to the study by Moeller and Schick (2006), Deaf children pass false belief tasks at younger ages (6- and 7-year-olds: $63 \%$ passed; 8- and 9-year-olds: $75 \%$ ) and native signers perform significantly better on ToM tasks than their late signers peers. The only study so far to compare native signers with their hearing peers at the same age was conducted by Courtin (2000), who studied ToM skills in a both native and late signers. It was discovered that the 5-and half-years-old native signers outperformed the 7-year-old late signers, regardless of whether the latter were learning sign language or spoken French. And what is more significant, native signers were significantly better on the false belief tasks than a control group of hearing peers. This results show an enhanced performance in Deaf children learning sign language because most sign languages (if not all) have grammatical structures to indicate the space, therefore, taking one's own or somebody else's perspective within the visual space is a basic element of the sign language grammar. Because of visual aspects of sign language, Deaf children learning sign language may be particularly advantaged when taking perspective of others as well as learning concepts about mental states.

As in the previous studies, Schick et al. 2007 found that the development in the field of understanding false beliefs and knowledge about mental states was delayed in the case of Deaf children of hearing parents, irrespective of a dominant language of an educational system (schools with spoken English or ALS). In contrast, native signers performed with no significant difference to the hearing children on any of the ToM tasks, either verbal or low verbal. This means that Deaf children with hearing parents are not delayed in ToM because of their Deafness per se. Early access to an equivalent language in 
another medium, namely ASL, is just as effective for communicating ToM, as demonstrated by native signers' performance. This study showed that early exposure to sign language is an important factor of ToM development but, in contrast to a finding by Courtin (2000), does not show that native signers are advantaged in their ToM development compared with their hearing peers, providing there was no evidence that sign language was facilitative over spoken language.

Hearing families that experience difficulty in communication with Deaf children about everyday routines also suffer extreme difficulty talking about thoughts, beliefs and intentions. As a result, language-delayed Deaf children miss out on references to abstract, unseen entities such as mental states, and have fewer raw materials to develop ToM concepts. Deaf children do not have any special problems with social interaction other than that imposed by delayed language skills, unlike children with autism, who have also been shown to be significantly delayed in ToM development (Peterson \& Siegal, 2000).

Deaf children of hearing parents usually grow up in an environment poor in stimulations, with low impact of engagement, and they are often treated as objects of speech therapy, which is connected with the more authoritarian way of communication that seems to focus on the parent's own wishes rather than the subject of personal dialogue in which the child' feelings and needs are respected. In such situations, Deaf children of hearing parents are usually deprived of any possibilities as well as a motivation to explain their own needs and make their own, independent decisions. What is more, they are often forced to communicate verbally with others. Such a contact and an early communication experience result in Deaf children's tendency to use repetitions and arguments that do not provide new information to their conversation partners and in their decreased ability to take the perspective of others.

In contrast to such a developmental pattern, Deaf children of Deaf parents who use a sign language as native (native signers) will not be at all delayed in ToM. Deaf children born to signing Deaf parents can develop natural and fluent communication skills as well as ToM (Marschark, et al., 2000; Gray \& Hosie, 1996). Native signers performed the same as hearing controls at ages 4, 5, and 6 years on both verbal and low verbal ToM tasks (Courtin, 2000; Peterson \& Siegel, 1997, 1999; Woolfe et al., 2002). Prelingually Deaf children, being born unable to hear but growing up in an environment rich with episodes of engagement, may be free of communication difficulties. 


\section{Communication competence of Deaf children's mothers in the context of his/her ToM development}

Several studies have found that relatively few hearing parents achieve sufficient proficiency in manual communication to converse fluently with their Deaf children about imaginary or unobservable objects as well as abstract concepts (Harris, 1992; Marschark, 1993).

Most Deaf children of hearing parents do not have access to sign language, because the social environment emphasizes oral communication which enables the child to communicate with other people by lip-reading using hearing remains supported by appropriate technical devices. Even if hearing parents can use sign language, their communication competence is poorly developed and communication limitations may have negative consequences for the understanding of the social world by Deaf children.

On the basis of retrospective statements of hearing parents of Deaf children Lundy (2002) concluded that only a small number of hearing parents can sign and that practically there is no difference in the level of theory of mind development between Deaf children of hearing parents who can sign and those who cannot sign. It suggests that the means of communication in families of Deaf children of hearing parents (just oral communication or including sign language) may not have any influence on the frequency of communication situations that engage thinking about others' thinking. The presence of a fluently signing partner or intensive training in natural sign language for hearing parents is therefore necessary.

Moeller (2002) has found that Deaf mother's signed use of mental state expressions (desires and cognitions) in describing events to their signing Deaf children is predictive of the children's ToM reasoning, independent of the children's own language skills. It means that a Deaf mother spontaneously stimulates theory of mind development of her Deaf child, even though his or her language competence is not highly developed. When engaging in conversations about mental states, a mother's signing skill impacts the frequency and diversity of these discussions.

Intensive and professional training in sign language for hearing mothers of Deaf children is a particularly significant factor influencing the development of the children's communication competence, which is in turn an important predictor of the development of language competence and theory of mind in Deaf children of pre-school age. Such conclusions can be drawn from recently 
published research conducted by Mary P. Moeller and Brenda Schick. The authors empirically proved the thesis proposed by Oliver Sacks (1998) that mother's actions have extreme consequences for the child's development, and that a complex and developed dialogue between mother and child determines whether the child's development will be appropriate. However attachment style is not determined by level of communication, language development, or maternal stress (Lederberg, 1993). Mother-child interaction during the first year or two depends more on the mother's ability to meet the child's needs than on the child's characteristics (i. e., the Deafness). Mother is sensitive to all nonverbal child's communicates which are important clues for the fulfillment of his/her basic needs. Mothers are equipped in intuitive parenting ability and intuitively tend to modify and adjust their behaviors to their Deaf child's cues, and by so doing, they facilitate communication and meet the child's needs better (Koester, Papousek, and Smith-Gray 2000). It might be a good predictor for the early symbiotic mother-child relationship as well as safe attachment.

The above quoted authors (Moeller, Schick, 2006) looked for correlations between theory of mind in Deaf children and the linguistic involvement of a hearing mother in the process of communication with a child. They analyzed free and directed messages of the mothers in the double system (oral and signing) expressed during play as well as describing pictures and cartoons. The researchers assessed the frequency with which the mothers used descriptions (both verbal and signing) referring to mental and extra-mental states, as well as the grammatical complexity of spontaneous statements of the children (nouns, verbs, questions and negations, sentence structures).

The analysis revealed very interesting correlations between the signing proficiency of the mothers (more extensive vocabulary related to mental states) and the level of ToM development of Deaf children and their better general language development. Hearing mother's use of sign language to name significant mental states has a crucial influence on the development of ToM in Deaf children, irrespective of the fact if the mother herself is a native signer or not. Moeller and Schick (2006) found that mothers of hearing children produced mental state terms significantly more often in conversation with their children than the mothers of Deaf children. Specifically, mothers of Deaf children did not produce much variety in the types of mental terms used in conversation, and those scoring below $75 \%$ on false-belief tasks used 
significantly fewer instances of mental state terms. In addition, mothers' signing ability significantly correlated with their talk about mental states and their history of participation in ASL classes. Also, maternal mental state input scores contributed significantly to Deaf children's false-belief understanding. Thus, training hearing mothers of first generation Deaf children in basic sign language signs describing mental states seems to be of paramount importance. As the mother is one of the most important significant others in early childhood as well the best model of language development, she exerts a very important influence on the value of her child's social interaction and ToM development. Results (Moeller, Schrick, 2006) showed that maternal signing proficiency was correlated with the child's language, false belief, and mothers' talk about the mind. Frequency of mothers' mental state talk was significantly related to ToM, after controlling for the effects of language. The frequency of maternal mental state input was influenced by the level of maternal sign skill.

Although initiating an interaction and communication with a Deaf child often motivates a mother to learn sign language, she is in many cases unable to communicate mental states to her child. Moeller and Schick (2006) found that hearing mothers varied in their ability to use signs for mental state terms and that the mothers' ability and willingness to talk about the mind was correlated with their own child's ability to pass false belief tasks. Deaf children of hearing mothers who use sign language in communication about mental states demonstrated only slight ToM delays in comparison to other studies.

Although Moeller and Schick (2006) measured mothers' manual signing skill, there was no measurement of the mothers' nonverbal communication ability. Sign language involves a special awareness of nonverbal communication cues; one extremely important nonverbal cue is facial expression (Emmorey, 1993). Facial expression is important to the syntax (arrangement of words) and morphology (structure and form of words) of sing language, where movements of the eyes, eyebrows, and mouth often determine what is being signed. For example, furrowing the eyebrows during a manual sign indicates the intent of questioning or inquiry, and is typically accompanied with "who", "what", "where", "when", and "why" questions. Unlike emotional facial expressions, which can be used by the speaker when and how he/she chooses, ASL grammatical facial expressions have a clear beginning and end, and are specifically coordinated with parts of the manual sign (Reilly, 
McIntire, \& Bellugi, 1990). For many manual signs, the same manual expression is used, but different facial expressions accompanying the manual sign distinguish the meaning (McCullough \& Emmorey, 1997). For example, during one manual sign, a natural facial expression indicates "for", whereas a facial expression furrowing the eyebrows indicates the question "what for?" In this example, the manual sign is the same, but what differs is the accompanying facial expression.

Siblings of Deaf children, both Deaf and hearing, might also play an important role in theory of mind development. It was found that the quality of the sibling relationship predicted ToM reasoning over and above the age of the children and the effectiveness of conversation about the physical world (Woolfe, 2002). Siblings of Deaf children can provide a positive environment in which children are exposed to talk about mental states that alerts them to the possibility that beliefs may differ from reality. Participating with siblings in pretend plays, Deaf children engage in numerous communicative situations that require describing mental states and reality. Children also might have an opportunity to confront the reality and false beliefs of another person.

Research has confirmed a developmental regularity described by BiałeckaPikul: ToM development if more dependent on communication competence than on the child's age. It has also indicated a significant influence of the family environment which participates in interactions with the child, especially of the signing mother and signing siblings. Mothers who signed more proficiently took part in professional training virtually from the moment they received the diagnosis and their higher social and economic status implied better understanding of the Deaf child's needs.

\section{Conclusions}

The above discussed studies indicate the specifics of ToM development in Deaf children depending on the family context. The majority of the studies verified two alternative hypotheses explaining the delay in that development. The relevance of those hypotheses - limited exposure to language and early conversational hypothesis - is closely linked to the functioning of the significant other, that is, the hearing mother, in relation to the Deaf child. The variety of existing studies in this field provokes further research questions.

More and more often the significant other who undertakes intensive care of a small child is the father. It would be interesting to see in what way his 
communication competence and intensity of interactions with the Deaf child influence ToM development.

Another group in close relation to Deaf children is the grandparents. Their behavior can also have important implications for ToM development and it would be worth researching.

It would be interesting from both cognitive and practical perspectives to replicate the studies conducted by Moeller and Schrick, 2006, in other countries. Is training in sign language equally effective in communities that use inflected languages?

\section{References}

Allyn \& Bacon. Jenkins, J. M., \& Astington, J. W. (1996). Cognitive Factors and Family Structure Associated with Theory of Mind Development in Young Children. Developmental Psychology, 32, 70-78.

Astington, J. W., \& Jenkins, J. M. (1999). A Longitudinal Study of the Relation Between Language and Theory of Mind Development. Developmental Psychology, 35, 1311-1320.

Baron-Cohen, S, (1995). Mindblindness: an Essay on Autism and Theory of Mind. MIT Press/Bradford Books.

Baron-Cohen, S., Jolliffe, T., Mortimore, C., \& Robertson, M. (1997). Another Advanced Test of Theory of Mind: Evidence from Very High Functioning Adults with Autism or Asperger Syndrome. Journal of Child Psychology and Psychiatry, 38, 813-822.

Baron-Cohen, S. (1995). Mindblindness: An Essay on Autism and Theory of Mind. Boston, MA: MIT Press/Bradford Books.

Baron-Cohen, S., Wheelwright, S., Jolliffe, T, (1997). Is There a "Language of the Eyes"? Evidence from Normal Adults, and Adults with Autism or Asperger Syndrome, Visual Cognition, 1997, 4 (3), 311-331

Baron-Cohen, S., O'Riordan, M., Stone, V., Jones, R. \& Plaisted, K. (1999). A New Test of Social Sensitivity: Detection of Faux Pas in Normal Children and Children with Asperger Syndrome: Journal of Autism and Developmental Disorders, 1999, 29, 407-418.

Białecka-Pikul, M. (2002). Co dzieci wiedza o umyśle i myśleniu. Badania i opis dziecięcej reprezentacji stanów mentalnych. Kraków: Wydawnictwo UJ.

Bowlby, J. (1969). Attachment and Loss: Vol. 1. Attachment. New York: Basic Books. Bretherton, I., and Beeghly, M. (1982). Talking about Internal 
States: The Acquisition of an Explicit Theory of Mind. Developmental Psychology, 18, (906-921).

Peterson, C. (2000). Kindred spirits: Influences of Siblings' Perspectives on Theory of Mind. Cognitive Development, 15, 4, 435-455

Courtin, C. (2000). The Impact of Sign Language on the Cognitive Development of Deaf Children: the Case of Theories of Mind. Journal of Deaf Studies and Deaf Education, 5(3), 266-276.

Courtin, C., \& Melot, A. M. (1998). Development of Theories of Mind in Deaf Children. In Marschark (Ed.), Psychological Perspectives on Deafness (pp. 79-102). Mahwah, NJ: Erlbaum.

Cutting, A. L., \& Dunn, J. (1999). Theory of Mind, Emotion Understanding, Language, and Family Background: Individual Differences and Interrelations. Child Development, 70, 853-865.

De Villiers, P. A., \& De Villiers, J. G. (2000). Linguistic Determinism and the Understanding of False Beliefs. In P. Mitchell \& K. Riggs (Eds.), Children's Reasoning and the Mind (pp. 191-228). Hove, UK: Psychology Press.

Dennett, D. (1978). Brainstorms. Montgomery, VT: Bradford. Emmorey, K. (1993). Processing a Dynamic Visual-spatial Lan- NSPB: 2007 - Vol. 5, No. 1

Dunn, J. (1991). Young Children's Understanding of Other People: Evidence from Observations within the Family. In D. Frye \& C. Moore (Eds.), Children's Theories of Mind (pp. 97-114). Hillsdale, NJ: Erlbaum.

Dykcik, W. (2001). Poszukiwanie nowatorskich i alternatywnych koncepcji indywidualnej rehabilitacji oraz społecznej integracji osób niepełnosprawnych - aktualnym wyzwaniem praktyki edukacyjnej. [In] W. Dykcik, B. Szychowiak (eds.). Nowatorskie i alternatywne metody w praktyce pedagogiki specjalnej, Poznań.

Emmorey, K. (1993). Processing a Dynamic Visual-spatial Language: Psycholinguistic Studies of American Sign Language. Journal of Psycholinguistic Research, 22, 153-187.

Fletcher, P. C., Happe, F., Frith, U., Baker, S. C., Dolan, R. J., Frackowiack, R. S. J., \& Frith, C. D. (1995). Other Minds in the Brain: A Functional Imaging Study of Theory of Mind in Story Comprehension. Cognition, 57, 109-128. Gleason, J. B. (Ed.) (2001). The Development of Language, 5th ed. Needham Heights, MA. 
Fonagy, P., Redfern, S., \& Charman, T. (1997). The Relationship Between Belief-desire Reasoning and a Projective Measure of Attachment Security (SAT). British Journal of Developmental Psychology, 15, 51-61.

Gray, C. D., Hosie, J. A.(1996). Deafness, Story Understanding, and Theory of Mind. Journal of Deaf Studies and Deaf Education, 1, 4, pp. 217-233.

Happé, F. G. E. (1994). An Advanced Test of Theory of Mind: Understanding of Story Characters' Thoughts and Feelings by Able Autistic, Mentally Handicapped and Normal Children and Adults. Journal of Autism and Developmental Disorders, 24, 129-154.

Harris, M. (1992). Language Experience and Early Language Development: from Input to Uptake. Hillsdale: Lawrence Erlbaum Association.

Jenkins, J. M., \& Astington, J. W. (1996). Cognitive Factors and Family Structure Associated with Theory of Mind Development in Young Children. Developmental Psychology, 32, 70-78.

Koester, L. S., Papoušek, H., and Smith-Gray, S. (2000). Intuitive Parenting, Communication, and Interaction with Deaf Infants. In P. E. Spencer, C. J. Erting, and M. Marschark (Eds.) The Deaf Child in the Family and at School: Essays in Honor of Kathryn P. Meadow-Orlans, (pp. 55-71). Mahwah, NJ: Lawrence Erlbaum Associates.

Lederberg, A. R. (1993). The Impact of Deafness on Mother-child and Peer Relationships. In M. Marschark \& D. Clark (Eds.), Psychological Perspectives on Deafness (pp. 93-119). Hillsdale, NJ: Lawrence Erlbaum.

Leslie, A. M. (1987). Pretense and Representation: The Origins of 'Theory of Mind.' Psychological Review, 94, 412-426.

Lewis, C., Freeman, N., Kyriakidou, C., Maridaki-Kassotaki, K., \& Berridge, D. M. (1996). Social Influences on False Belief Access: Specific Sibling Influences or General Apprenticeship? Child Development, 67, 2930-2947.

Lundy, J. E. B. (2002). Age and Language Skills of Deaf Children in Relation to Theory of Mind Development. Journal of Deaf Studies and Education, 7, 41-56.

Marschark, M. (1993). Psychological Development of Deaf Children. New York: Oxford University Press. McCullough, S., \& Emmorey, K. (1997). Face Processing by Deaf ASL Signers: Evidence for Expertise in Distinguishing Local Features. Journal of Deaf Studies and Deaf Education, 2, 212-222. 
Marschark, M., Green, V., Hindmarch, G., \& Walker, S. (2000). Understanding Theory of Mind in Children Who Are Deaf. Journal of Child Psychology and Psychiatry, 41(8), 1067-1073.

McAlister, A., Peterson, C. (2007). A Longitudinal Study of Child Siblings and Theory of Mind Development. Cognitive Development, 22, 258-270

McCullough, S., \& Emmorey, K. (1997). Face Processing by Deaf ASL Signers: Evidence for Expertise in Distinguishing Local Features. Journal of Deaf Studies \& Deaf Education, 2(4), 212-222.

Meadow, K. P., Greenberg, M. T., Erting, C., \& Carmichael, H. (1981). Interactions of Deaf Mothers and Deaf Preschool Children: Comparisons with Three Other Groups of Deaf and Hearing Dyads. American Annals of the Deaf, 126, 454-468.

Meins, E., \& Fernyhough, C. (1999). Linguistic Acquisitional Style and Mentalizing Development. Cognitive Development, 14, 363-380.

Taumoepeau, M., Ruffman, T. (2008).Stepping Stones to Others' Minds: Maternal Talk Relates to Child Mental State. Language and Emotion Understanding at 15, 24, and 33 Months. Child Development, March/ April 2008, Volume 79, Number 2, Pages 284-302.

Milligan, K., Astington, J. W., \& Dack, L. A. (2007). Language and Theory of Mind: Meta-analysis of the Relation Between Language Ability and False-belief Understanding. Child Development, 78, 622-646.

Moeller, M. P., \& Schick, B. (2006). Relations Between Maternal NSPB: 2007 - Vol. 5, No. 170 Theory of Mind Input and Theory of Mind Understanding in Deaf Children. Child Development, 77, 751-766.

Perner, J., Ruffman, T., \& Leekam, S. R. (1994). Theory of Mind Is Contagious: You Catch It from Your Sibs. Child Development, 65, 1228-1288.

Perner, J. \& Wimmer, H. (1985) “John Thinks that Mary Thinks that...” Attribution of Second-order Beliefs by 5-10 Year Old Children. Journal of Experimental Child Psychology, 39, 437-471.

Peterson, C. C. (2004). Theory-of-mind Development in Oral Deaf Children with Cochlear Implants or Conventional Hearing Aids. Journal of Child Psychology and Psychiatry, 45, 1096-1106.

Peterson, C. C., \& Siegal, M. (1995). Deafness, Conversation and Theory of Mind. Journal of Child Psychology and Psychiatry, 36, 459-474.

Peterson, C. C., \& Siegal, M. (1997). Psychological, Physical, and Biological Thinking in Normal, Autistic, and Deaf Children. In H. M. Wellman 
\& K. Inagaki (Eds.), The Emergence of Core Domains of Thought: Children's Reasoning about Physical, Psychological, and Biological Phenomena (New Directions for Child Development, No. 75) (pp. 55-70). San Francisco: Jossey-Bass

Peterson, C. C., \& Siegal, M. (1999). Representing Inner Worlds: Theories of Mind in Deaf, Autistic and Normal Hearing Children. Psychological Science, 10, 126-129.

Peterson, C. C., \& Siegal, M. (2000). Insights into Theory of Mind from Deafness and Autism. Mind and Language, 15, 123-145.

Pettito, L. A., \& Marentette, P. F. (1991). Babbling in the Manual Mode: Evidence for the Ontogeny of Language. Science, 251, 1493-1496.

Plopa, M. (2004). Psychologia rodziny: teoria i badania. Kraków: Oficyna wydawnicza "Impuls".

Premack, D. C., \& Woodruff, G. (1978). Does the Chimpanzee Have a Theory of Mind? Behavioural and Brain Sciences, 1, 516-526.

Reilly, J. S., McIntire, M., \& Bellugi, U. (1990). The Acquisition of Conditionals in American Sign Language: Grammaticized Facial Expressions. Applied Psycholinguistics, 11, 369-392.

Ruffman, T., Perner, J., Naito, M., Parkin, L., Clements, W.A. (1998). Older (But Not Younger) Siblings Facilitate False Belief Understanding. Developmental Psychology, 34, 161-174.

Ruffman, T., Slade, L., \& Crowe, E. (2002). The Relation Between Children's and Mothers' Mental State Language and Theory-of Mind Understanding. Child Development, 73, 734-751.

Russell, J. A., Hosie, C. D., Gray, C., Scott, C., Hunter, N., Banks, J. S., $\&$ Macaualy, M. C. (1998). The Development of Theory of Mind in Deaf Children. Journal of Child Psychology and Psychiatry, 39, 903-910.

Sacks. O (1998). Zobaczyć głos. Wydawnictwo Zysk i S-ka, Poznań, 1998

Schick, B., de Villiers, P. de Villiers, J. \& Hoffmeister, R. (2007). Language and Theory of Mind: A Study of Deaf Children. Child Development, 78(2), 376-396. NSPB: 2007 - Vol. 5, No. 1.

Sullivan, K., D. Zaitchik and H. Tager-Flusberg (1994), "Preschoolers Can Attribute Second Order Beliefs", Developmental Psychology, vol 30, no 3, 395-402.

Tager-Flusberg, H. (1999). The Challenge of Studying Language Development in Children with Autism. In L. Menn \& N. Bernstein Ratner (Eds.), Meth- 
ods for Studying Language Production. Mahwah, NJ: Lawrence Erlbaum Associates.

Taumoepeau, M., \& Ruffman, T. (2006). Mother and Infant Talk about Mental States Relates to Desire Language and Emotion Understanding. Child Development, 77, 465-481.

Taumoepeau, M., \& Ruffman, T. (2008). Stepping Stones to Others' Minds: Maternal Talk Relates to Child Mental State Language and Emotion Understanding at 15, 24 and 33 Months. Child development, 79(2), 284-302.

Tomasello, M., Kruger, A. C., \& Ratner, H. H. (1993). Cultural Learning. Behavioral and Brain Sciences, 16, 495-552.

Twardowski A., 2003, Wczesne wspomaganie rodzin wychowujących dzieci niepełnosprawne intelektualnie, (w:) red. Z. Janiszewska-Nieścioruk, Człowiek z niepełnosprawnością intelektualną, t. I, Oficyna Wyd. "Impuls", Kraków. 101-111.

Vaccari, C., \& Marschark, M. (1997). Communication Between Parents and Deaf Children: Implications for Social-emotional Development. Journal of Child Psychology and Psychiatry, 38, 793-801.

Watkins, S., Pittman, P., \& Walden, B. (1998). The Deaf Mentor Experimental Project for Young Children Who Are Deaf and Their Families. American Annals of the Deaf, 143(1), 29-34.

Welch-Ross, M. K. (1997). Mother-child Participation in Conversation about the Past: Relationships to Preschoolers' Theory of Mind. Developmental Psychology, 33, 618-629.

Wellman, H. M. \& Estes, D. (1986). Early Understanding of Mental Entities: A Reexamination of Childhood Realism. Child Development, 57, 910-923.

WIMMER, H., \& PERNER, J. (1983). Beliefs about Beliefs: Representation and Constraining Function of Wrong Beliefs in Young Children's Understanding of Perception. Cognition, 13, pp. 103-128.

Woolfe, T., Want, S. C. \& Siegal, M. (2002) Signposts to Development: Theory of Mind in Deaf Children. 73(3). pp. 768-778.

\section{Contact}

Joanna Kossewska, PhD,

Department of Psychology

Pedagogical Univeristy

Podchorążych 2

30-084 Kraków, Poland

e-mail: Joanna.Kossewska@ap.krakow.pl 